\title{
Emissions of a Euro 5 motorcycle over the world harmonized motorcycle test cycle (WMTC)
}

The Euro 5 limits for L-category vehicles are applicable since 2020 and for this reason there is lack of studies examining the emissions of this category. In this study we tested a $1000 \mathrm{~cm}^{3}$ Euro 5 motorcycle over the World Harmonized Motorcycle Test Cycle (WMTC). The gaseous pollutants were approximately half of their respective limits. The cold start (first 2 minutes) contributed to the majority of the emissions. The solid particle number emissions were also 6.5 times below the limit for passenger cars, but the particles not counted with the current methodology were around 2 times higher. High concentrations of volatiles were emitted at the high speed part of the cycle.

Key words: L-category, motorcycle, particle emissions, fuel consumption, WMTC

\section{Introduction}

Registered mopeds (engine displacement $<50 \mathrm{~cm}^{3}$ ) and motorcycles, collectively called powered two-wheelers (PTWs) accounted for more than 35 million vehicles in EU28 in 2017 , more than $10 \%$ of the passengers' mobility fleet $[1,2]$. More than $25 \%$ of the PTWs are registered in Italy. In Europe, the share of households holding PTWs in 2015 was $10 \%-25 \%$ [3]. The annual registrations of motorcycles in the EU increased in recent years, exceeding one million both in 2018 and 2019. The registrations of mopeds, which are one third of the motorcycles, on the other hand decreased. The relative contribution of mopeds and motorcycles to air pollution started to increase as the levels from other vehicles started to decrease.

In 2013, Regulation (EU) No 168/2013 and in 2014, supplemental technical Regulation (EU) 134/2014 established implementation dates for Euro 4 (2016) and Euro 5 (2020) L-category vehicles (i.e. 2-, 3-and 4-wheelers such as mopeds, motorcycles, quads and minicar). The Euro 5 emission limits are at the same levels with the limits of passenger cars, but, in contrast to passenger cars, solid particle number (SPN) emissions are not regulated. Due to their recent introduction in the market, to the authors knowledge there are no published data in the literature regarding Euro 5 motorcycles. Speculations for the expected improvements can be found though [4]. The data on Euro 4 motorcycles, which also have to respect strict limits under the same cycle and protocol are also limited [4-6].

The respective laboratory cycle is the WMTC (world harmonized motorcycle test cycle), which is based on actual on-road driving profiles. For this reason, the laboratory emissions are expected to be closer to the real world emissions. The WMTC consists of urban, rural and motorway (highway) parts. Many studies give big emphasis to the urban emissions, where the population exposure is the highest [7]. When laboratory and real-world cycles are compared, it is important to compare the respective parts (e.g. urban real world cycles with the urban parts of the laboratory cycles).

The aim of this paper is to summarize the emissions of a Euro 5 motorcycle giving separately the emissions of the urban, rural and motorway parts. Special emphasis is given to the particle number emissions, which are not regulated for the specific motorcycle.

\section{Materials and methods}

\subsection{Motorcycle}

The motorcycle was Euro 5 type approved, with $1 \mathrm{~L}$ engine displacement, $115 \mathrm{~kW}$ max power at $10,500 \mathrm{rpm}$ and $105 \mathrm{Nm}$ max torque at $9000 \mathrm{rpm}$, with $5000 \mathrm{~km}$ on the odometer. It belonged to the high-performance motorcycles category (L3e-A3) because the power/weight ratio was $>0.2 \mathrm{~kW} / \mathrm{kg}$, and the maximum power $>35 \mathrm{~kW}$. It had manual transmission, electronic injection and three-way catalyst.

The empty mass was $200 \mathrm{~kg}$ and an inertia of $290 \mathrm{~kg}$ was used for testing. Reference gasoline fuel with 5\% ethanol content was used with density $0.743 \mathrm{~kg} / 1\left(15^{\circ} \mathrm{C}\right)$.

\subsection{Laboratory}

The tests were conducted at the Vehicle Emissions Laboratory (VELA 1) of the European Commission - Joint Research Centre (JRC) (Ispra, Italy), at an ambient temperature of $23-25^{\circ} \mathrm{C}$ and relative humidity of $45 \%-55 \%$. The exhaust of the motorcycle was diluted in a full dilution tunnel with constant volume sampling (CVS), which was set to $5.5 \mathrm{~m}^{3} / \mathrm{min}$ (Fig. 1).

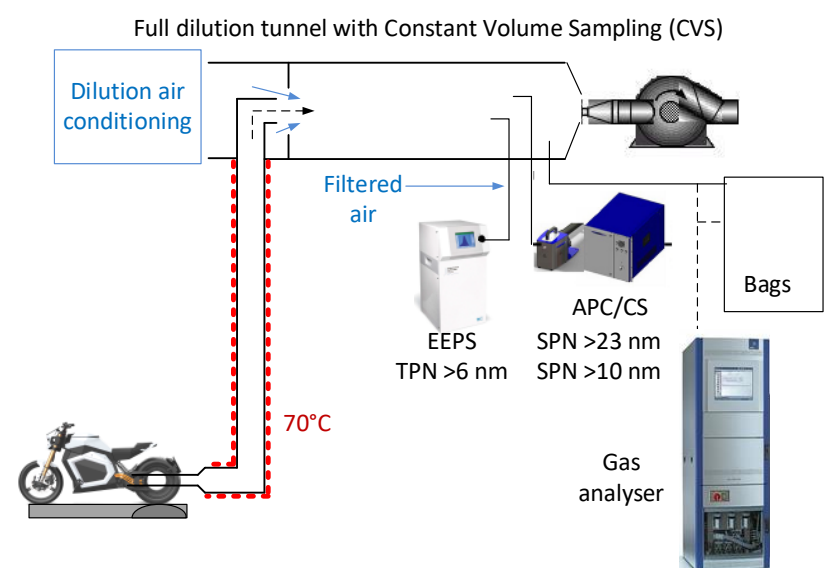

Fig. 1. Experimental setup 
The gaseous pollutants were measured from the dilution tunnel in real time with analyzers AMA i60 (from AVL, Graz, Austria). Furthermore, a small part of the diluted gas was also collected in bags and was analyzed for the gaseous pollutants at the end of the cycle with the same set of analyzers. The principle of operation of the analyzers was: non-dispersive infrared detection for carbon monoxide (CO) and carbon dioxide $\left(\mathrm{CO}_{2}\right)$, chemiluminescence for nitrogen oxides $\left(\mathrm{NO}_{\mathrm{x}}\right)$, and hot $\left(191^{\circ} \mathrm{C}\right)$ flame ionization detection for total hydrocarbons ( $\mathrm{HC})$ and methane $\left(\mathrm{CH}_{4}\right)$. Non-methane hydrocarbons (NMHC) were calculated from the difference of $\mathrm{HC}$ and $\mathrm{CH}_{4}$.

An AVL particle counter (APC) 489 (AVL, Graz, Austria) [8], compliant with the light-duty vehicle regulations, was connected to the dilution tunnel. The system consisted of a hot diluter at $150^{\circ} \mathrm{C}$, a catalytic stripper at $350^{\circ} \mathrm{C}$ [9], and a final porous diluter operating with room-temperature filtered air. For sub-23 nm, a catalytic stripper is necessary for the removal of volatile particles according to the latest Global Technical Regulation (GTR 15) for light-duty vehicles $[10,11]$. The applied particle number concentration reduction factor $(\mathrm{PCRF})$ was $500(50 \times 10)$. The PCRF was determined by the manufacturer during the calibration of the instrument and combined the dilution and average particle losses at 30, 50 and $100 \mathrm{~nm}$, as required in the lightduty vehicles regulation. Downstream of the second dilution two TSI (Shoreview, MN, USA) butanol condensation particle counters (CPCs) with $50 \%$ counting efficiency at $23 \mathrm{~nm}$ (model 3790) and 65\% efficiency at $10 \mathrm{~nm}$ (model 3772) were used to measure the PN concentrations of solid particles > $23($ SPN > $23 \mathrm{~nm})$ and $>10 \mathrm{~nm}($ SPN $>10 \mathrm{~nm})$, respectively. The specific counting efficiencies are defined in GTR 15 [11].

An engine exhaust particle sizer (EEPS) (model 3090 from TSI) was connected to the full dilution tunnel using a simple diluter (dilution ratios 65-75:1). Such high dilution was necessary to avoid saturation at the last part of the cycle. The EEPS measured particle size distributions from 5.6 to $560 \mathrm{~nm}$, based on particle charging and measuring their current at the electrometers where they deposited. As there was no thermal treatment, all particles (i.e., solids and volatiles) were measured (TPN $>6 \mathrm{~nm}$ ).

\subsection{Test cycle}

The cycle was the WMTC (World Harmonized Motorcycle Test Cycle) stage 2, class 3, sub-class 3-2. The WMTC was introduced with Euro 4 and is based on actual driving patterns. Some characteristics of the cycle can be found in Table 1.

The cycle consisted of three phases (Fig. 2): Phase 1 or urban part, phase 2 or rural part, and phase 3 or motorway (highway) part (details in Table 1). Each phase was $10 \mathrm{~min}$ long (600 s) with a total cycle duration of $30 \mathrm{~min}(1800 \mathrm{~s})$. The mean speed was $24.4 \mathrm{~km} / \mathrm{h}$ in the urban phase, 54.7 $\mathrm{km} / \mathrm{h}$ in the rural, and $94.4 \mathrm{~km} / \mathrm{h}$ in the motorway phase. For the calculations of the cycle emissions, the weighing factors of phase 1 and phase 3 were $25 \%$, and $50 \%$ for phase 2 , as prescribed in the regulation.

The motorcycle was soaked at $23^{\circ} \mathrm{C}$ overnight and the test started with the engine at ambient temperature (cold start).
Table 1. Characteristics of the WMTC and its phases

\begin{tabular}{|l|c|c|c|c|}
\hline & Phase 1 & Phase 2 & Phase 3 & WMTC \\
\hline Duration [s] & 600 & 600 & 600 & 1800 \\
\hline Distance [km] & 4.1 & 9.1 & 15.7 & 28.9 \\
\hline Mean speed [km/h] & 24.4 & 54.7 & 94.4 & 57.8 \\
\hline Weighing factor [-] & 0.25 & 0.5 & 0.25 & - \\
\hline
\end{tabular}

\subsection{Calculations}

The emissions E were calculated from the real time signals from the dilution tunnel:

$$
E_{j, k}=\left(\sum_{k} C_{j, i, c} \rho_{j} Q_{i}\right) / D_{k}
$$

where $\mathrm{j}$ is the pollutant, $\mathrm{k}$ is the phase (urban, rural, motorway). $C_{j, i, c}$ is the background corrected concentration of the pollutant $j$ at time $i, \rho_{j}$ is the density of the pollutant, $Q_{i}$ is the dilution tunnel flow rate, $D_{k}$ is the distance of the phase. The fuel consumption (FC) was given from the equation given in Regulation (EU) No 134/2014:

$\mathrm{FC}=(0.848 \mathrm{HC}+0.429 \mathrm{CO}+0.273 \mathrm{CO} 2) 0.118 / \rho$

where $\rho$ is the fuel density.

\section{Results}

Figure 2 plots the speed profile and the exhaust gas temperature at the tailpipe. Figure 3 gives examples of real time emissions of regulated pollutants. The cold start emissions are high because the catalyst has not reached its lightoff temperature. After the first two minutes the emissions are low, with relatively higher emissions during the motorway part.

Figure 4 plots the weighed WMTC results for the regulated pollutants. The emission levels were $45-60 \%$ of the respective limits.

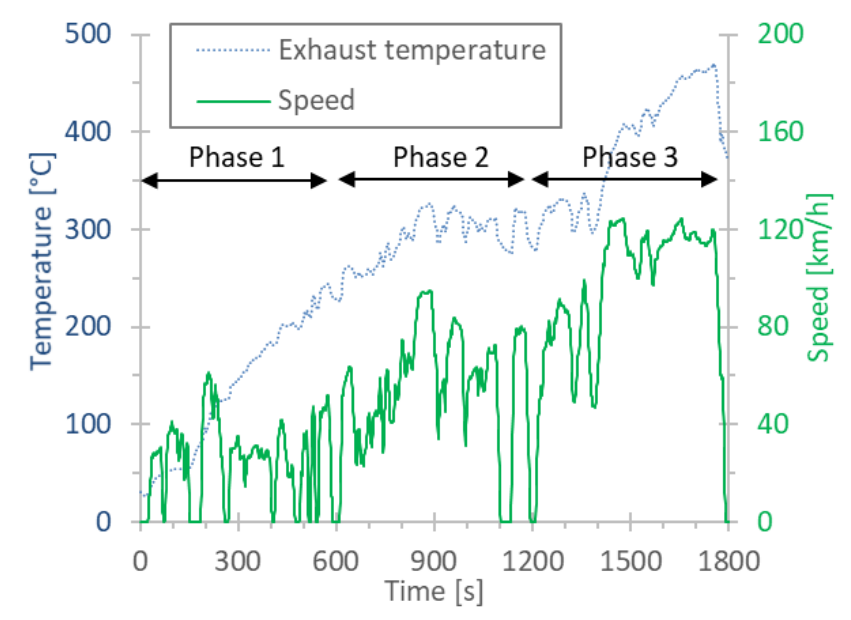

Fig. 2. Speed profile and exhaust gas temperature at the tailpipe

Figure 5 plots the particle number (PN) signals as measured from the dilution tunnel.

The solid particle number (SPN) emissions of particles $>23 \mathrm{~nm}$ and $>10 \mathrm{~nm}$ followed the speed profile, with high spikes during accelerations. High emissions were noted at the cold start. The motorway part had also high emissions, but there the dilution at the dilution tunnel is lower due to the higher exhaust flow rate. Due to the high speed, the distance specific SPN emissions were relatively low. 

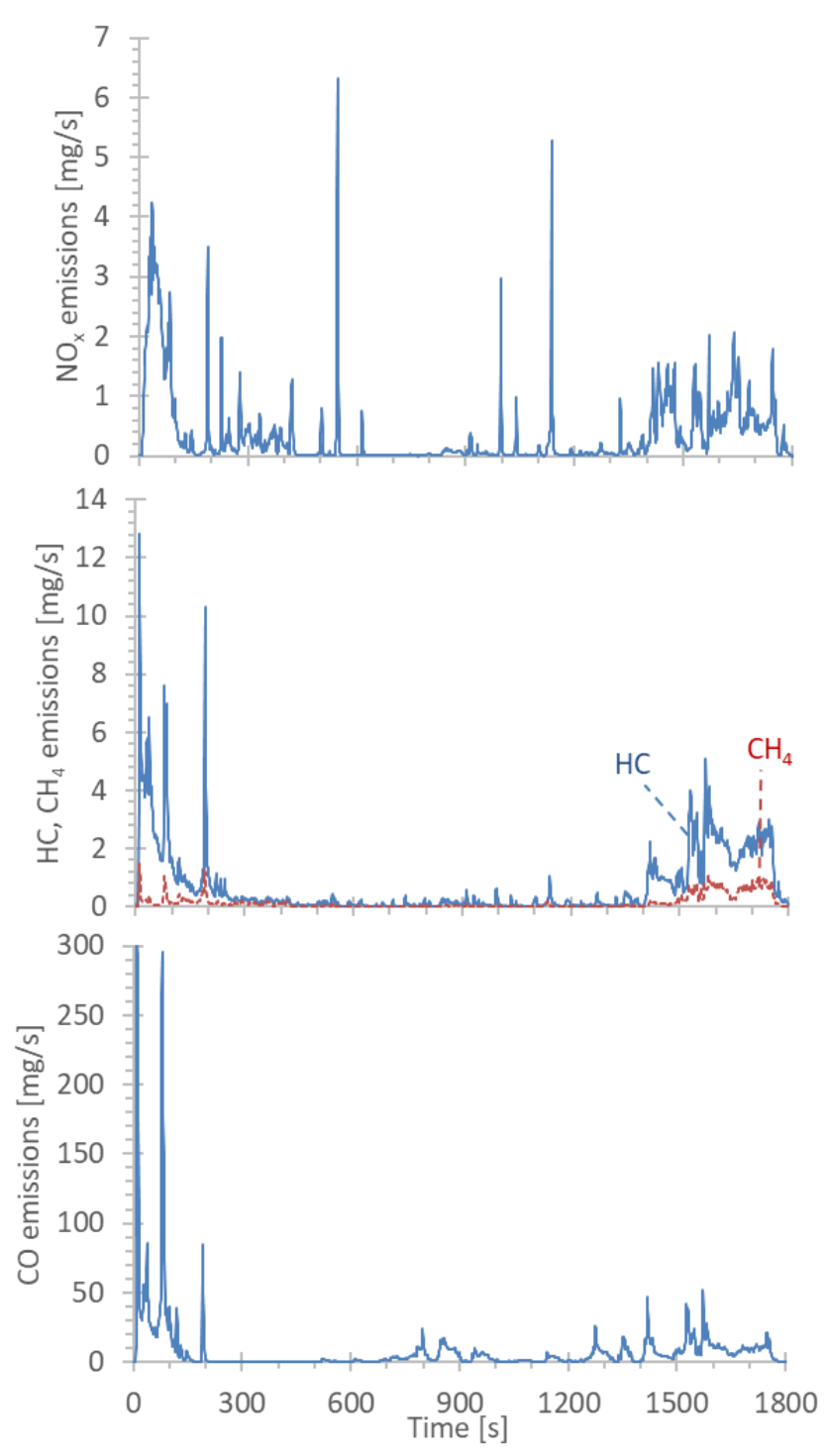

Fig. 3. Real time emissions of $\mathrm{NO}_{x}$ (upper panel), $\mathrm{HC}$ and $\mathrm{CH}_{4}$ (middle panel) and $\mathrm{CO}$ (lower panel)

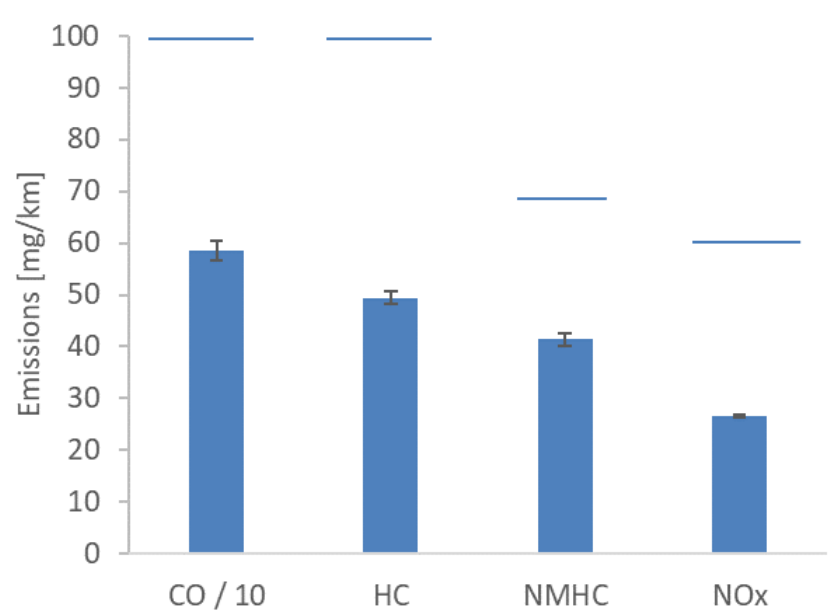

Fig. 4. Emission results of regulated pollutants. Blue bars give the motorcycle Euro 5 limits. Error bars show min-max of two repetitions. CO emissions and emission limit are divided with 10

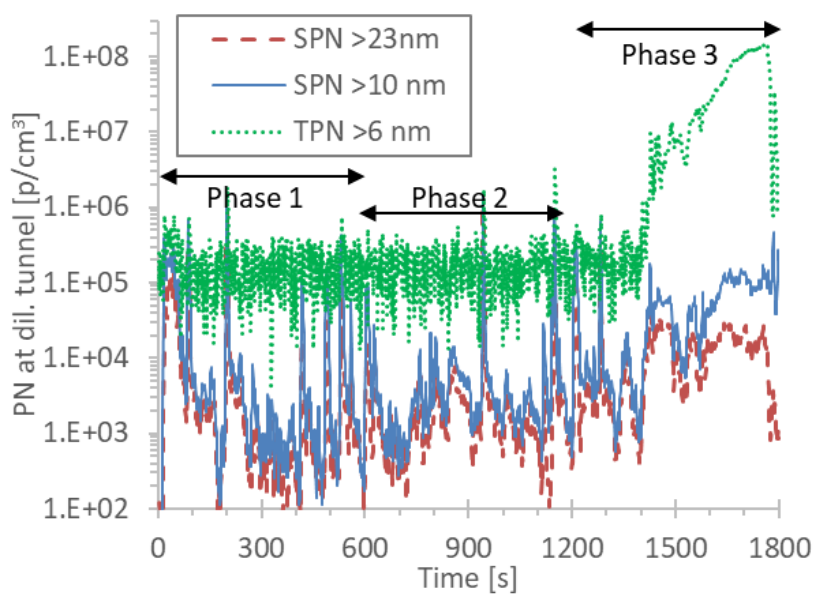

Fig. 5. Particle number (PN) emissions for solid (SPN) or total (TPN) particles as measured from the dilution tunnel. To convert to $\mathrm{p} / \mathrm{s}$ multiply by $1.0 \mathrm{E}+05$

The total particle number (TPN) emissions were measured with the EEPS without any thermal pre-treatment. Due to the high dilution used (around 70:1) and the high detection limit of the instrument, the background levels were even higher than the spikes of the SPN instruments at the urban and rural parts. At the motorway part a high increase of volatile particles occurred. This coincided with the increase of the exhaust gas temperature $>350^{\circ} \mathrm{C}$ (see Fig. 1).

The results of the gaseous pollutants, particles, fuel consumption and $\mathrm{CO}_{2}$ are summarized in Table 2 .

Table 2. Emission results for the WMTC and its phases. FC = fuel consumption; SPN = solid particle number; TPN = total particle number

\begin{tabular}{|l|c|c|c|c|}
\hline & Phase 1 & Phase 2 & Phase 3 & WMTC \\
\hline $\mathrm{CO}[\mathrm{mg} / \mathrm{km}]$ & 1687 & 176 & 302 & 585 \\
\hline $\mathrm{NO}_{\mathrm{x}}[\mathrm{mg} / \mathrm{km}]$ & 77 & 6 & 17 & 27 \\
\hline $\mathrm{HC}[\mathrm{mg} / \mathrm{km}]$ & 141 & 6 & 44 & 49 \\
\hline $\mathrm{CH}_{4}[\mathrm{mg} / \mathrm{km}]$ & 19 & 1 & 11 & 8 \\
\hline $\mathrm{NMHC}[\mathrm{mg} / \mathrm{km}]$ & 122 & 5 & 33 & 41 \\
\hline $\mathrm{CO}_{2}[\mathrm{~g} / \mathrm{km}]$ & 197 & 112 & 119 & 135 \\
\hline $\mathrm{FC}[1 / 100 \mathrm{~km}]$ & 8.7 & 4.9 & 5.2 & 5.9 \\
\hline $\mathrm{SPN}_{10} 10^{11}[\mathrm{p} / \mathrm{km}]$ & 5.3 & 0.75 & 2.5 & 2.3 \\
\hline $\mathrm{SPN}_{23} 10^{11}[\mathrm{p} / \mathrm{km}]$ & 2.2 & 0.35 & 0.52 & 0.87 \\
\hline $\mathrm{TPN}_{6} 10^{11}[\mathrm{p} / \mathrm{km}]$ & 25 & 11 & 1560 & 400 \\
\hline
\end{tabular}

\section{Discussion}

Emission factors were low but there are a few points that need further investigation. One is how these emissions change over time. There were no durability requirements for Euro 3 or older motorcycles and significant increases of the emissions with mileage accumulation have been reported [12]. Durability mileage, also indicated as useful life values, as determined in Annex VII of Regulation (EU) No $168 / 2013$, is $35,000 \mathrm{~km}$ for motorcycles with maximum speed $>130 \mathrm{~km} / \mathrm{h}$. The Euro 5 deterioration factors are 1.3 for the regulated pollutants. This would mean that a $30 \%$ increase is expected until the end of the useful life of the motorcycle, but the emissions still have to respect the limits.

The second point is how close are the laboratory emissions to the real-world emissions. A few studies have found differences with older (and smaller) motorcycles, type approved with the older cycles [7]. More research is needed as 
portable equipment will become available [13], in particular for Euro 5 motorcycles type approved with the WMTC, which is based on actual driving patterns and thus smaller differences are expected [14]. It is important to notice though that any comparison between laboratory and onroad tests needs to compare the real-world emissions with the appropriate part of the laboratory cycle (e.g. city emissions with the urban part). Table 2 gave the emissions of each part of the WMTC, and it is clear that there are big differences in emission levels between the different parts.

Another point is the high increase of volatiles when the exhaust gas temperature exceeded $350^{\circ} \mathrm{C}$. At such high temperatures any deposited or desorbed material in the transfer line could be released. It can be assumed that the released material nucleated during cooling and dilution in the full dilution tunnel and resulted in high particle concentrations. Such desorption and high concentration of nucleation mode particles was reported in a dedicated study on the influence of the transfer line on particulate emissions [15]. In our study the geometric mean dimeter of these particles was $17-24 \mathrm{~nm}$. Another study with a Euro 4 motorcycle [16] found also such high volatile particles concentration, but when they repeated with an open configuration (i.e. dilution at the tailpipe) no such volatile particles appeared. It still needs to be understood whether these particles are produced from the motorcycle and due to the desorption they increase in size when they cool down at the dilution tunnel or they are an artefact of the sampling lines [17]. Nevertheless, the solid particle emissions > $23 \mathrm{~nm}$ were much lower (6.5 times) than the emission limit of the passenger cars (but 2.5 times when considering solid particles $>10 \mathrm{~nm}$ ). The CLOVE proposal for Euro 7 for passenger cars is $1 \times 10^{11} \mathrm{p} / \mathrm{km}$ (for $\mathrm{SPN}_{10}$ ). CLOVE (Consortium for ultra Low Vehicle Emissions) is the consortium tasked by the European Commission to give guidelines for the upcoming Euro 7 emission standards. The motorcycle exceeded this limit 2.5 times, indicating that the particle number emissions from L-category vehicles will need to be reconsidered.

\section{Conclusions}

This is one of the first studies of a Euro 5 motorcycle. The gaseous pollutants were half of their respective limits. The solid particle number emissions were $6.5(23 \mathrm{~nm})$ and $2.5(10 \mathrm{~nm})$ times lower than the limits of passenger cars (not applicable to motorcycles). The emissions per phase (urban, rural, motorway) parts were also provided. For all pollutants the cold start had the highest contribution, while the motorway part was a significant source of total particles. More research is needed for total particles to ensure that they are not an artefact of the high exhaust gas temperatures and release of deposited materials in the sampling lines.

\section{Acknowledgements}

The authors would like to acknowledge the technical support of A. Bonamin, D. Lesueur, and F. Forloni.

\section{Nomenclature}

APC AVL particle counter

$\mathrm{CH}_{4}$ methane

$\mathrm{CO}$ carbon monoxide

$\mathrm{CO}_{2}$ carbon dioxide

CPC condensation particle counter

CVS constant volume sampler

EEPS engine exhaust particle sizer

FC fuel consumption

GTR global technical regulation
HC hydrocarbons

NMHC non-methane hydrocarbons

$\mathrm{NO}_{x} \quad$ nitrogen oxides

PCRF particle concentration reduction factor

PN particle number

PTW powered two-wheelers

SPN solid particle number

TPN total particle number

WMTC world harmonized motorcycle test cycle

\section{Bibliography}

[1] ACEM Association Des Constructeurs Européens de Motocycles. Market Data. Available at: https://www.acem.eu/Market-Data 2019

[2] EUROPEAN COMMISSION. Directorate General for Mobility and Transport EU Transport in Figures: Statistical Pocketbook. 2018. ISBN 978-92-79-73951-4

[3] DOROCKI, S. Changes in the market of two and threewheeled motor vehicles in Europe at the beginning of the 21st century. EBER. 2018, 6, 175-193. https://doi.org/10.15678/EBER.2018.060110

[4] KONTSES, A., NTZIACHRISTOS, L., ZARDINI, A.A. et al. Particulate emissions from L-category vehicles towards Euro 5. Environmental Research. 2020, 182, 109071. https://doi.org/10.1016/j.envres.2019.109071

[5] NTZIACHRISTOS, L., VONK, W.A., PAPADOPOULOS, G. et al. Effect study of the environmental step Euro 5 for L-category vehicles. European Commission. 2017, ISBN 978-92-79-70203-7.

[6] GIECHASKIEL, B., ZARDINI, A.A., LÄHDE, T. et al. Particulate emissions of Euro 4 motorcycles and sampling considerations. Atmosphere. 2019, 10, 421. https://doi.org/10.3390/atmos10070421

[7] CHIANG, H.-L., HUANG, P.-H., LAI, Y.-M. et al. Comparison of the Regulated Air Pollutant Emission Characteristics of Real-World Driving Cycle and ECE cycle for motorcycles. Atmospheric Environment. 2014, 87, 1-9. https://doi.org/10.1016/j.atmosenv.2013.12.031

[8] GIECHASKIEL, B., CRESNOVERH, M., JÖRGL, H. et al. Calibration and accuracy of a particle number measurement system. Measurement Science and Technology. 2010, 21, 045102. https://doi.org/10.1088/0957-0233/21/4/045102

[9] AMANATIDIS, S., NTZIACHRISTOS, L., GIECHASKIEL, B. et al. Evaluation of an oxidation catalyst ("catalytic stripper") in eliminating volatile material from combustion aerosol. Journal of Aerosol Science. 2013, 57, 144-155. https://doi.org/10.1016/j.jaerosci.2012.12.001 
[10] GIECHASKIEL, B., MELAS, A.D., LÄHDE, T. et al. Nonvolatile particle number emission measurements with catalytic strippers: a review. Vehicles. 2020, 2, 342-364. https://doi.org/10.3390/vehicles2020019

[11] LAHDE, T., GIECHASKIEL, B., MARTINI, G. Development of measurement methodology for sub $23 \mathrm{~nm}$ particle number (PN) measurements. SAE Technical Paper 2020-012211. 2020. https://doi.org//10.4271/2020-01-2211

[12] TSAI, J.-H., HUANG, P.-H., CHIANG, H.-L. Air pollutants and toxic emissions of various mileage motorcycles for ECE driving cycles. Atmospheric Environment. 2017, 153, 126134. https://doi.org/10.1016/j.atmosenv.2017.01.019

[13] VOJTISEK-LOM, M., ZARDINI, A.A., PECHOUT, M. et al. A miniature portable emissions measurement system (PEMS) for real-driving monitoring of motorcycles. Atmospheric Measurement Techniques. 2020, 13, 5827-5843. https://doi.org/10.5194/amt-13-5827-2020

Barouch Giechaskiel, PhD - Sustainable Transport Unit, European Commission, Joint Research Centre (JRC), Italy.

e-mail: barouch.giechaskiel@ec.europa.eu
[14] MURENA, F., PRATI, M.V., COSTAGLIOLA, M.A. Real driving emissions of a scooter and a passenger car in Naples city. Transportation Research Part D: Transport and Environment $2019, \mathbf{7 3}, 46-55$.

https://doi.org/10.1016/j.trd.2019.06.002

[15] YANG, J., PHAM, L., JOHNSON, K.C. et al. Impacts of exhaust transfer system contamination on particulate matter measurements. Emission Control Science and Technology. 2020, 6, 163-177.

https://doi.org/10.1007/s40825-020-00155-1

[16] GIECHASKIEL, B. Gaseous and particulate Emissions of a Euro 4 motorcycle and effect of driving style and open or closed sampling configuration. Sustainability. 2020, 12, 9122. https://doi.org/10.3390/su12219122

[17] GIECHASKIEL, B. Effect of sampling conditions on the sub-23 nm nonvolatile particle emissions measurements of a moped. Applied Sciences. 2019, 9, 3112. https://doi.org/10.3390/app9153112

Anastasios Melas, PhD - Sustainable Transport Unit, European Commission, Joint Research Centre (JRC), Italy.

e-mail: anastasios.melas@ec.europa.eu 